\title{
Experience of Massive Distance Online Education for Medical Colleges and Universities in China to Counter the COVID-19 Pandemic
}

\section{Jiyang Zhao}

Education depatment of Harbin medical university https://orcid.org/0000-0002-8190-1083

Hai Xiao

Education Department of Harbin medical university

\section{Yong Li}

Education Department of Harbin medical university

\section{Da Wen}

Education Department of Harbin medical universtiy

\section{Peixiang $\mathrm{Xu}$}

Education Department of Harbin medical university

\section{Yao Fu}

Education Department of Harbin medical university

Jie Piao

Education Department of Harbin medical university

Jiangheng Liu

Education Department of Harbin medical university

\section{Depin Cao}

https://orcid.org/0000-0002-8253-6057

\section{Zhaohua Zhong}

Education Department of Harbin medical university

Guang Zhao ( $\nabla$ zhaog662003@126.com )

Education Department of Harbin Medical University

\section{Research article}

Keywords: Distance online education, Teaching platforms, Replace traditional classroom education

Posted Date: July 8th, 2020

DOI: https://doi.org/10.21203/rs.3.rs-29678/v1 
License: (c) (i) This work is licensed under a Creative Commons Attribution 4.0 International License. Read Full License 


\section{Abstract \\ Background}

As the COVID-19 outbreak influenced teaching in China, Chinese medical colleges and universities carried out massive online education with the participants of more than one million students on the for-profit or non-profit big-data teaching platforms, based on existing online teaching resources and other ways such as MOOC, Micro-course, Live-course and interactive discussion.

\section{Methods}

A questionnaire survey was conducted via two rounds of 56-in-total questions on overall situations, platforms, teaching methods, training, teachers and students' experiences, and encountered problems for 1747 teachers and 7223 students, which involved 741 courses. Comparative analysis was done on the survey results.

\section{Results}

A majority of teachers and students were satisfied with teaching platforms and effects; large commercial teaching platforms could provide better services; $67.21 \%$ of teachers and $64.67 \%$ of students preferred live teaching; only $76.84 \%$ of teachers and $58.69 \%$ of students were systematically trained; weak network, lack of training, overcrowded access to teaching platforms, lack of interaction, lack of efficient real-time evaluation and fatigue were current difficulties.

\section{Conclusions}

Good results of massive distance online education and teachers and students' satisfaction with teaching platform performance show that online education can be used as a main means to replace traditional classroom education in emergency situations.

\section{Background}

At the end of 2019, a sudden outbreak of viral pneumonia epidemic caused by a novel coronavirus occurred in central China. To effectively control the spread of the viruses, the local government locked down the entire city of Wuhan, the capital of Hubei Province, China on January 23, 2020, just two days before the traditional celebration of lunar new year. Soon enough, the whole country became blocked due to every provincial government initiated the first-class response measurement against the coronavirus pandemic. The lockdown turned out to be the most effective action to stop the disease's spreading, however, hundreds and thousands of various schools, from elementary schools to universities all over the 
country, were also shut down because their students could not return from the four- to six-week winter break.

To counter the potential impact of COVID-19 on school education, distance online teaching and learning became the only option of feasible solution. In fact, almost every educational institution launched online teaching activities from February to March 2002, unprecedented in the history of the world, to nearly 200 million students in total.

Online education, also called distance education or online learning, generally refers to a network-based learning activity [1], by which the teachers and students can carry out teaching and learning through internet even thousands of miles apart [2]. Without limit of time and space, students can learn courses via e-learning platform and interactive communication platform, by either live broadcasting or recorded video resources. With the advent of mobile widgets, WIFI, cellular networks, and big databases, teaching and learning become more and more digitally and diversified. Technology has profoundly transformed the traditional offline study with various online strategies, such as Small Private Online Course (SPOC) and Massive Open Online Courses (MOOC). SPOC and MOOC have widely adopted in higher education institutions and have significantly strengthened the efficiency and quality of learning through, e.g., fragmented learning and role reversal of teachers and students [3].

Internationally, since 2012, three major platforms represented by Coursera, Udacity, and eDX have been gradually implemented in higher education institutions including 62 top universities around the world, and have gradually become an online education mode with for-profit and non-profit education institutions, which has been promoted in the field of higher education around the world. In China, online education has also flourished. The Ministry of Education of China (MOE) has issued relevant incentive policies and established goals for developing online education and online course construction. Teaching platforms such as Chaoxing Learning (chaoxing.com), Zhihuishu (www.zhihuishu.com), and Chinese University MOOC have begun their industrialized and commercialized operation stages and have achieved successfully. Meanwhile, the rapid development of social media platforms such as Alibaba and Tencent in China has also greatly strengthened the feasibility of massive online education in China.

Harbin Medical University (HMU), located in northeastern China and with over 16,000 students and graduates in campus, is one of the leading medical universities in China. $\mathrm{HMU}$ is one of the Chinese universities at the earliest to launch massive online teaching and learning to counter the COVID-19 pandemic. HMU started the distance online education activities from February 17, 2020. Up to March 22, $2020,3,571$ online class teaching for 741 courses have been done, over 214,181 online student-users participated the online study. According to various surveillance, the quality of teaching and learning is basically identical to the campus offline study. Hereby we summarized one of our surveys about the distance online teaching and learning to our faculties and students. Given that so many countries have suffered from the COVID-19 pandemic recently, distance online study is going to be adopted in these countries, our experience may be a help to the universities in these countries. 


\section{Methods}

Two rounds of surveys were launched to 1,747 faculties and 7,223 students of $\mathrm{HMU}$, respectively, through WeChat-based questionnaires [4]. The surveys, with a total of 56 questions, covered 723 online classes from February 17 to March 16, 2020. The questions mainly involved class efficiency, platforms, teaching methods, relevant training, experiences and problems about distance online teaching and learning. The majors of faculties and students included clinical medicine, public health, basic medical sciences, and pharmacology, etc. To respect the privacy of the participants, all participants were informed that the personal information would not be included in the data analysis.

\section{Results}

\section{Overall situation of massive online courses}

To the date of the surveys, about 2451 online classes, 723 courses have been given in HMU. About $95.59 \%$ of planned courses in the academic calendar in that period were finished with online study. About 153,151 online student-users and 2,451 online faculty-users participated online study. According to our survey, $98.48 \%$ of faculties and $98.50 \%$ of students were satisfied with online teaching/learning platforms. About $98.70 \%$ of faculties and students were satisfied with online outcome (Table 1). Our survey suggests that distance online teaching/learning is an effective solution for university students during emergency situations.

\section{Usage Of Massive Online Teaching Platforms}

There was a high degree of consistency in the selection of online teaching platforms for teachers and students. There was higher usage of interactive online teaching platforms such as Tencent Classroom(https://ke.qq.com/s), Tencent Meeting(https://cloud.tencent.com/), WeChat(https://weixin.qq.com/) and DingTalk(https://www.dingtalk.com/) etc. which were similar to eDX, Lark and Skype etc., reaching more than $20 \%$ for each. Teachers had the highest usage rate of Alibaba's DingTalk software, reaching 34.96\%, on the contrary, professional online teaching platforms, represented by Icourse163, Zhihuishu, Rain Classroom, only accounted for $8.12 \%, 14.07 \%$ and $8.33 \%$ (Fig. 1).

\section{Methods Of Massive Online Education}

Currently massive online teaching methods mainly included three forms: live teaching, online resources, and answering questions. Survey data showed that $67.21 \%$ of teachers and $64.67 \%$ of students believed that live teaching was better than online resources, because the teaching purpose of live teaching with video playback function was different from online resources or MOOCs (Fig. 2). The education objects of online resources or MOOCs were mainly the public [5], that is to say, people outside the campus and its 
teaching objectives were the popularization of education. However, massive online education was mainly a teaching mode for improving or guaranteeing teaching quality by education institutions. Online education was closer to traditional classroom teaching [6], which got more recognition of students. Meanwhile, online education could not only ensure its timeliness and interaction to a certain extent [7, 8], but also could help students repeatedly study the least understood contents after class. Therefore, it was recommended using live teaching methods for online education.

Most teachers and students considered that a reasonable online teaching time was 30-60 minutes (Fig. 3). Because of teaching media, space limitations and different interactive teaching methods, teachers couldn't immediately know about students' leaning results by students' performance, so that the pace was faster; teachers were nervous or uncomfortable to face the screen or camera for a long time, so that some of them tend to speak faster; holding a posture for a long time to teach and learn resulted in physical fatigue and inability to concentrate for a long time and affected the teaching effect [9]. Therefore, massive online instructors should carefully select and reorganize teaching contents and schedule, instead of replicating traditional classroom teaching mode. When teachers and students couldn't stay focused well, some links such as test or interaction etc. could be set to reduce the negative impact of long-term online education on teaching and learning.

Besides, teachers and students' manipulation of learning equipment should also be noticed in the process of online education [10]. Since teachers and students could operate their own equipment, the time and requirements for teachers and students to operate teaching equipment should be clarified in the pre-class training to avoid confusion in the teaching order caused by teachers and students speaking and typing at the same time. Data showed that students should turn off video and voice while teachers were speaking, and only turn on their screens and microphones when discussing or speaking. It could reduce the pressure on the Internet and maintain a smooth teaching order.

\section{Pre-class Training For Teachers And Students}

According to the survey, we found that more than one-fifth of teachers and one-third of students were not given sufficient training before the official class, which resulted in teachers and students not being able to focus on teaching and learning (Fig. 4). As a result, we can speculate that the effectiveness of training for teachers and students is closely related to the quality of online education [11, 12]. In addition, the proportion of students who did not receive training before the lecture was larger than that of teachers. This showed that the school usually trained teachers adequately, but neglected the training of students. If online education was to be continued or conducted in other countries, this issue should be paid special attention to.

\section{Problems To Be Solved In Online Education}


It could be seen from the survey data that about $28.35 \%$ of teachers and $31.11 \%$ of students agreed that "Weak network access" and $37.33 \%$ of teachers and $41.19 \%$ of students agreed that "overcrowded access to teaching platform", which reminded us that although massive online education could be implemented smoothly, web environment and software and hardware needed further optimization and upgrade. Besides, teachers focused more on the problems of teaching order and teaching quality such as "Lack of training" (33.45\%), "Lack of interaction" (44.24\%), and "Lack of efficient real-time evaluation" (56.48\%), which were future studies on massive online education. It was worth noting that quite a few students "Fatigue" (53.75\%), and some teachers also agreed with it (Fig. 5). In the questionnaire survey, some teachers and students mentioned that this phenomenon was that due to the massive online education for the first time, teachers and students were not familiar with online teaching and learning, resulting in part of strangeness and anxiety [13].

\section{Discussion}

Online education has been introduced and used worldwide for at least more than two decades. Online education has also widened the public's access to professional expertise and knowledge that usually can only be available for students in universities and colleges. In the campuses, online education has been employed as a supportive learning method. However, during lockdown period for stopping the pandemic of COVID-19 in early 2020, online education became the only applicable way to continue the teaching and learning in Chinese universities and colleges.

A massive online education has been launched in Harbin Medical University that has lasted over seven weeks so far. Through a quick training in $\mathrm{HMU}$, a basic framework for massive online education has been developed in all colleges and departments, which mainly includes two parts: an online classroom using various electronic conference platforms, and a supportive online tool for real-time test and questionnaire. It gives a chance to the faculty members and students to learn how to effectively use the online education facility and environment. We did two rounds of survey to our faculty members and students to learning how it worked and how they felt. Our experience may be helpful to colleagues worldwide, given that the COVID-19 pandemic has turned out to be a global health disaster and many countries have to lock down all activities to prevent the spreading of the viruses.

In terms of overall performance, the teachers and students were basically satisfied with the functions and performance of these networks and learning tools. Surprisingly, the pause caused by network access seldom occurred in our online classes. Almost all students could receive clear signals all the time. Considering that over 0.2 billion students from various levels of schools national wide were online simultaneously, it is impressive that the nation's infrastructure can easily handle such a huge pressure. From this case, we believe that online education is an applicable solution for higher education to counter a pandemic emergency such as COVID-19.

Comparing the performance of professional online E-learning platforms and commercial network services, it is interesting, according to our surveys, that the E-learning platforms could not effectively 
handle the massive access pressure as commercial networks did. The commercial platforms such as Alibaba, Tencent, etc., can easily cope with huge traffic and many simultaneous online teaching processes, which performs far better than the E-learning platforms including some official E-course platforms established by governmental funds. Although the design of the E-learning platforms is more in line with the concepts of pedagogy and teaching/learning conditions, nonetheless, it traditionally defines itself as an aid but not the main arena to academic study. There is no comparability between the Elearning platforms and commercial platforms in terms of technology, technical workers, and funds. Academic education can be novel and huge market for commercial network services in future.

Quite a few teachers and students worry about the network environment and learning equipment during the survey [14]. In developing countries like China, there still exist uneven economic development and a clear gap between rich and poor. Some students have no extra money to purchase high-quality E-learning equipment or mobile network traffic due to family financial issues. It is extremely important to provide financial support to these students prior to the online study. The solution to these problems is to subsidize students by setting up special funds to reduce the impact on the quality and effects of online education due to economic reasons. As an example, Harbin Medical University has offered about $\$ 400,000$ to support students buying electronic widgets and network service.

In online education, "visiting" (teachers' classroom observation or students auditing a course) is an interesting and noteworthy further-researched phenomenon [15]. Quite a number of teaching administrators, fellow teachers, students' parents, as well as some students who do not need, have actively participated in the online learning of the course. It seems that different people have different purposes for online education. Teaching administrators are mostly to evaluate teaching operation and course quality; the peer teachers mainly think it beneficial to learn teaching methods and gain online teaching experience; students' parents are to monitor students' learning status; students who do not need aim to enrich their knowledge and broaden their horizon via re-learning. Researchers suggest that this "social facilitation effect" of online education can optimize national knowledge system and improve national competence, which has excellent social service benefits and deserves attention and promotion.

There is limitation in the surveys. The administrators co-ordinate various staffs and resources in the massive online learning to guarantee the event going smoothly, but the role played by the administrators has not been considered.

\section{Conclusions}

Taken together, in the case of global emergency of COVID-19 pandemic, massive online education can effectively replace campus study and neutralize the negative impact to the lockdown.

\section{Abbreviations}

COVID-19 
Corona Virus Disease 2019; SPOC:Small Private Online Course; MOOC:Massive Open Online Courses; MOE:The Ministry of Education of China; HMU:Harbin Medical University

\section{Declarations}

\section{Ethics approval and consent to participate}

The research described in the article had ethical approval from the Ethics Committee of Harbin Medical University. This was an online survey about the massive distance online education to the faculties and students of the universities and completion of the questionnaire implied consent. The requirement for written or oral consent was waived by the Ethics committee, and implied consent for those included in the questionnaire was also approved by the Ethics committee.

\section{Consent for publication}

All authors have read the article and agree to publish.

\section{Availability of data and materials}

The datasets are available upon request.

\section{Competing interests}

No competing interests.

\section{Funding}

The study was supported financially by the Higher Education Teaching Reform Project of Heilongjiang (SJGY20170405, Education Department of Heilongjiang Province, China), which aims to encourage medical colleges and universities to carry out the research on teaching models and methods. The funding body assisted with technical services and software support in our study.

\section{Authors' Contributions}

JYZ, HX, DPC, ZG and ZZH were responsible for the study concept and design. YL, DW, PXX, YF, JP and $\mathrm{JHL}$ were involved in the design and launch of the surveys. JYZ and HX made substantial contributions to the data acquisition, management and statistical analysis. JYZ and ZZH drafted the first version of the manuscript. DPC and ZG revised the manuscript critically. All authors approved the final version of the manuscript and agreed to be accountable for all aspects of the work. 


\section{Acknowledgements}

We would like to thank all the faculties and students who made contribution to the surveys. We thank Education Department of Heilongjiang Province, China, for financial support.

\section{Author details}

${ }^{1}$ Education Department, Harbin Medical University, Harbin 150081, China.

\section{References}

1. Mark Bullen. What's the difference? A review of contemporary research on the effectiveness of distance learning in higher education. Journal of Distance Education. 1999;14(1):102-14.

2. Masic I, Pandza H, Masic Z. Medical Informatics Education and Distance Learning at Sarajevo Biomedical faculties. Ukraininan Journal of Telemedicine Telematics. 2008;6(3):131-4.

3. Pickering JD, Henningsohn L, DeRuiter MC, de Jong PG, Reinders ME. Twelve tips for developing and delivering a massive open online course in medical education. Med Teach. 2017;39(7):691-6.

4. Ruyu Xia X, Willcox HM, Li X, Li Y, Wang J, Li X, Moore M, Liu J, Yutong Fei. How far do we still need to go? A survey on knowledge, attitudes, practice related to antimicrobial stewardship regulations among Chinese doctors in 2012 and 2016. BMJ Open. 2019;9:e027687.

5. Masters K. A brief guide to understanding MOOCs. Int J Med Educ. 2011;1(2):2.

6. Coma del Corral MJ, Guevara JC, Luquin PA, Pena HJ, Mateos Otero JJ. Usefulness of an Internetbased thematic learning network: Comparison of effectiveness with traditional teaching. Med Informatics. 2006;31:59-66.

7. Pei L. Hongbin Wu. Does online learning work better than offline learning in undergraduate medical education? A systematic review and meta-analysis. Med Educ Online. 2019;4(1):1666538.

8. Mącznik AK, Ribeiro DC, Baxter GD. Online technology use in physiotherapy teaching and learning: a systematic review of effectiveness and users' perceptions. BMC Med Educ. 2015;28(15):160.

9. Chen C-M, Wang J-Y. Chih-Ming Yu. Assessing the Attention Levels of Students by Using a Novel Attention Aware System Based on Brainwave Signals. Br J Edu Technol. 2017;48(2):348-69.

10. Locatis C, Gaines C, Liu WL, Gill M, Carney J, Foster J, McCall V, Woods M. A blended training approach using videoconferencing for distance education. J Med Libr Assoc. 2006;94(4):464-8.

11. Masic I. E-Learning as New Method of Medical Education. Acta Inform Med. 2008;16(2):102-17.

12. Lall P, Rees R, Law GCY, Dunleavy G, Cotič Ž, Car J. Influences on the Implementation of Mobile Learning for Medical and Nursing Education: Qualitative Systematic Review by the Digital Health Education Collaboration. J Med Internet Res. 2019;21(2):e12895.

13. Elliott RA, McDowel J, Marriott JL, Calandra A, Duncan G. A Pharmacy Preregistration Course Using Online Teaching and Learning Methods. Am J Pharm Educ. 2009;73(5):77. 
14. Frehywot S, Vovides Y, Talib Z, Mikhail N, Ross H, Wohltjen H, Bedada S, Korhumel K, Koumare AK, Scott J. E-learning in medical education in resource constrained low- and middle-income countries. Hum Resour Health. 2013;11:4.

15. Erdmann RM, Stains M. Classroom as Genome: Using the Tools of Genomics and Bioinformatics to Illuminate Classroom Observation Data. CBE Life Sci Educ. 2019;18(1):es1.

\section{Figures}

\section{Teaching platform}

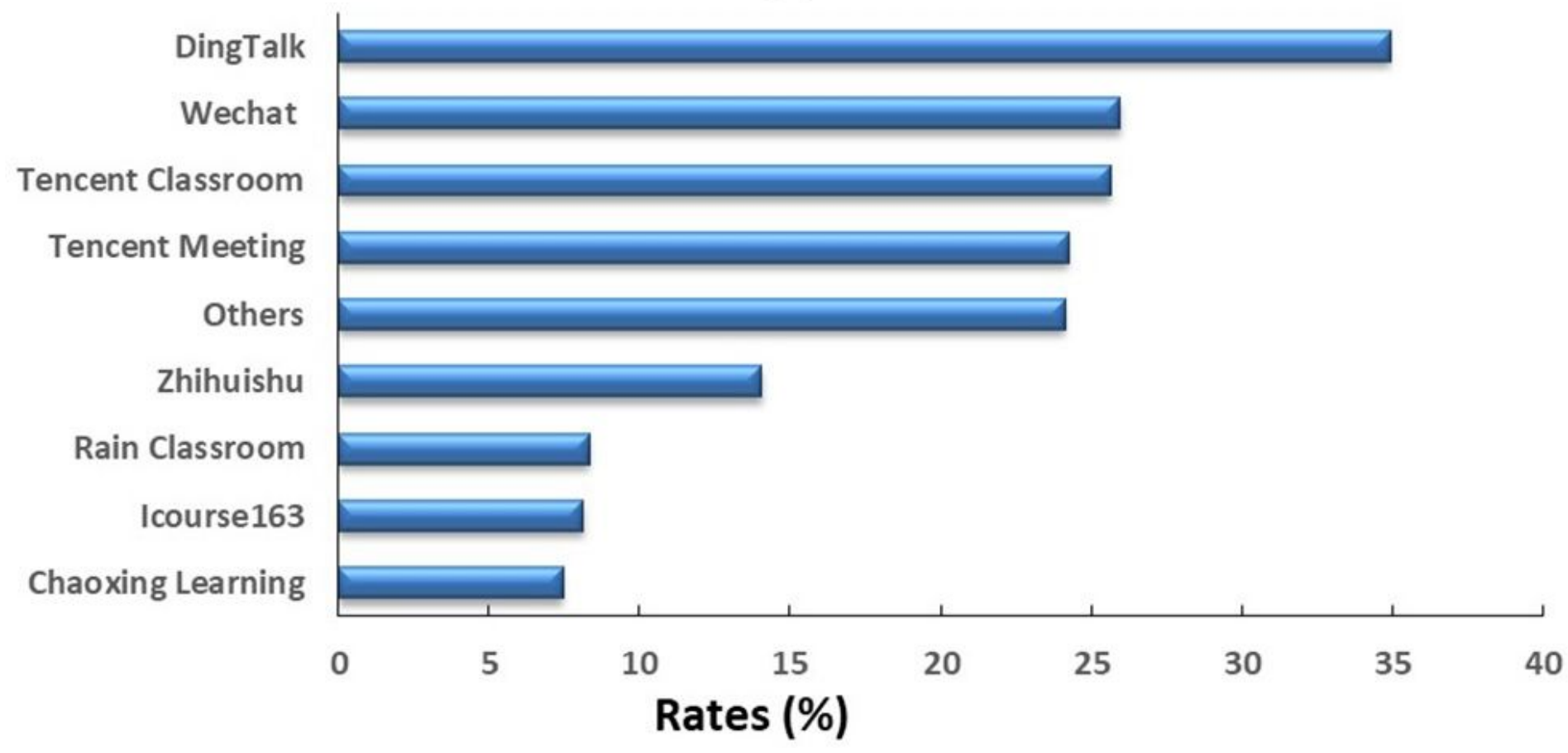

\section{Figure 1}

Overview of teaching platforms, including the platform name and percentage of usage. The rate of platforms was $34.96 \%$ for Dingtalk and $25.97 \%$ for Wechat, $25.65 \%$ for Tencent Classroom and $24.24 \%$ for Tencent Meeting, $14.07 \%$ for Zhihuishu and $8.33 \%$ for Rain Classroom, $8.12 \%$ for Icourse 163 and Chaoxing Learning for $7.47 \%$ and $24.13 \%$ for Others. 


\section{Teaching Method}

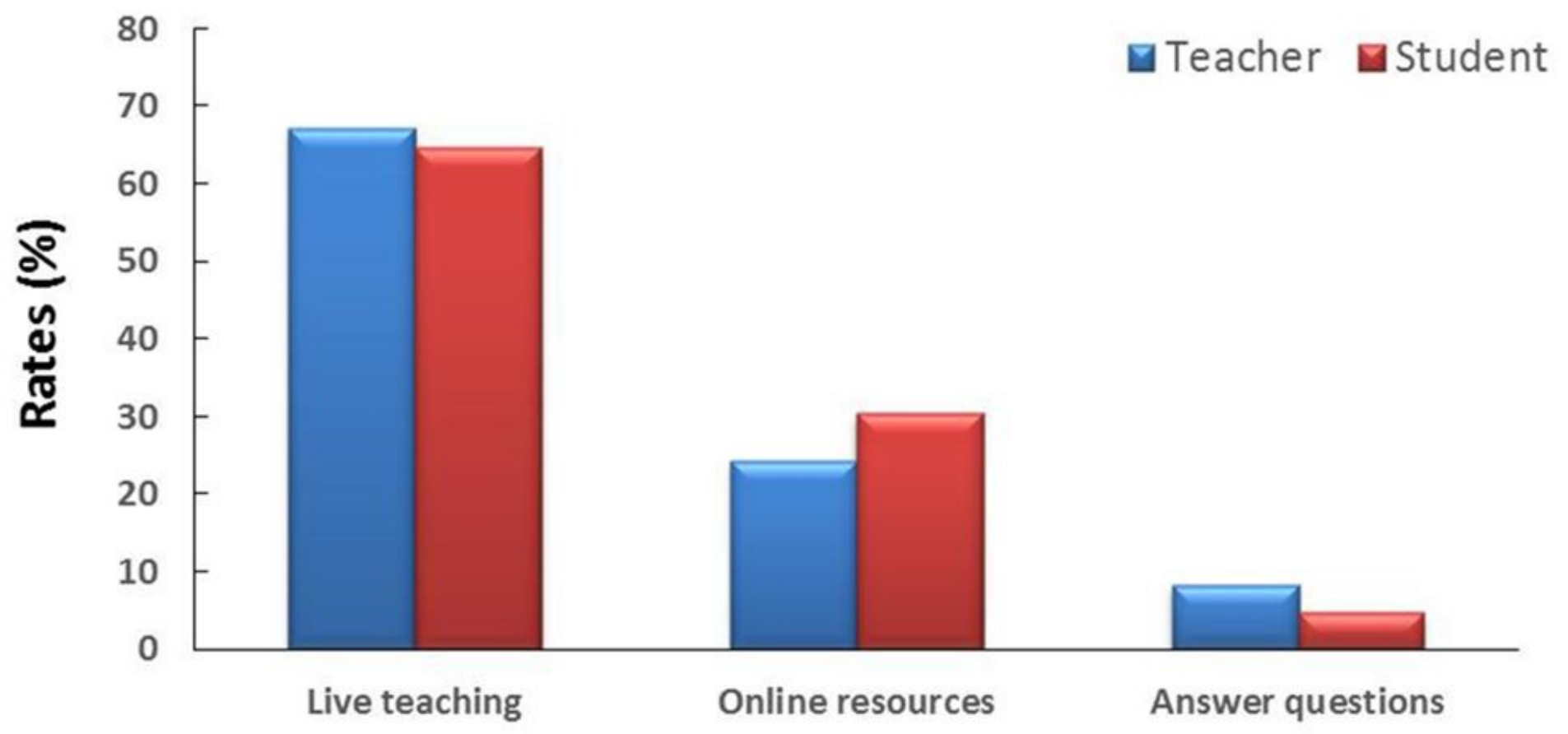

Figure 2

Views of teachers and students about teaching methods in the massive distance online education. $67.1 \%$ of teachers and $64.67 \%$ of students believed that live teaching was better than online resources and answer questions.

\section{Reasonable teaching time}

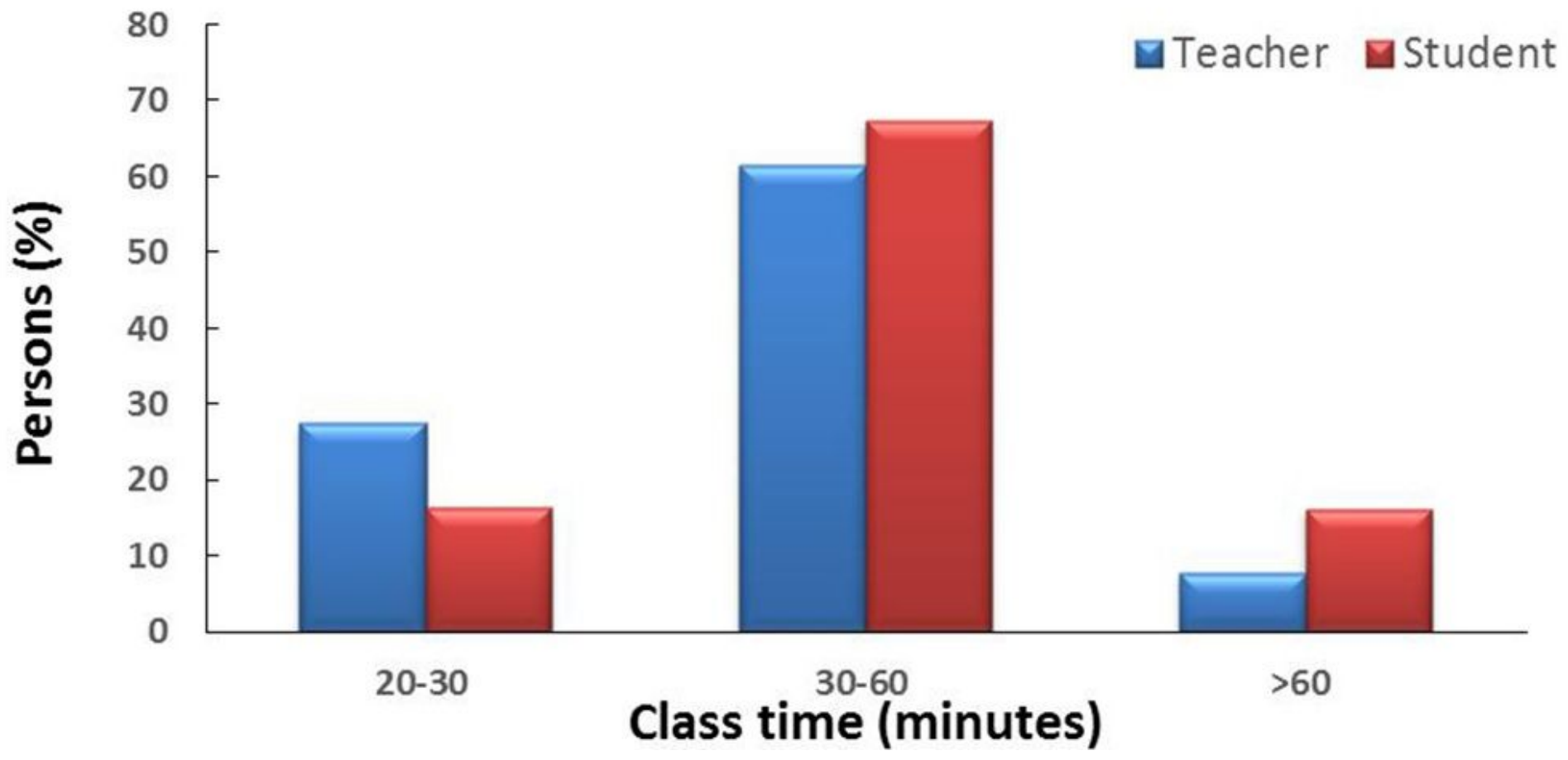




\section{Figure 3}

Overview of teachers and students about reasonable teaching time in the massive distance online education. $61.61 \%$ of teachers and $67.41 \%$ of students believed that $30-60$ minutes should be the reasonable teaching time for each class.

\section{Training}

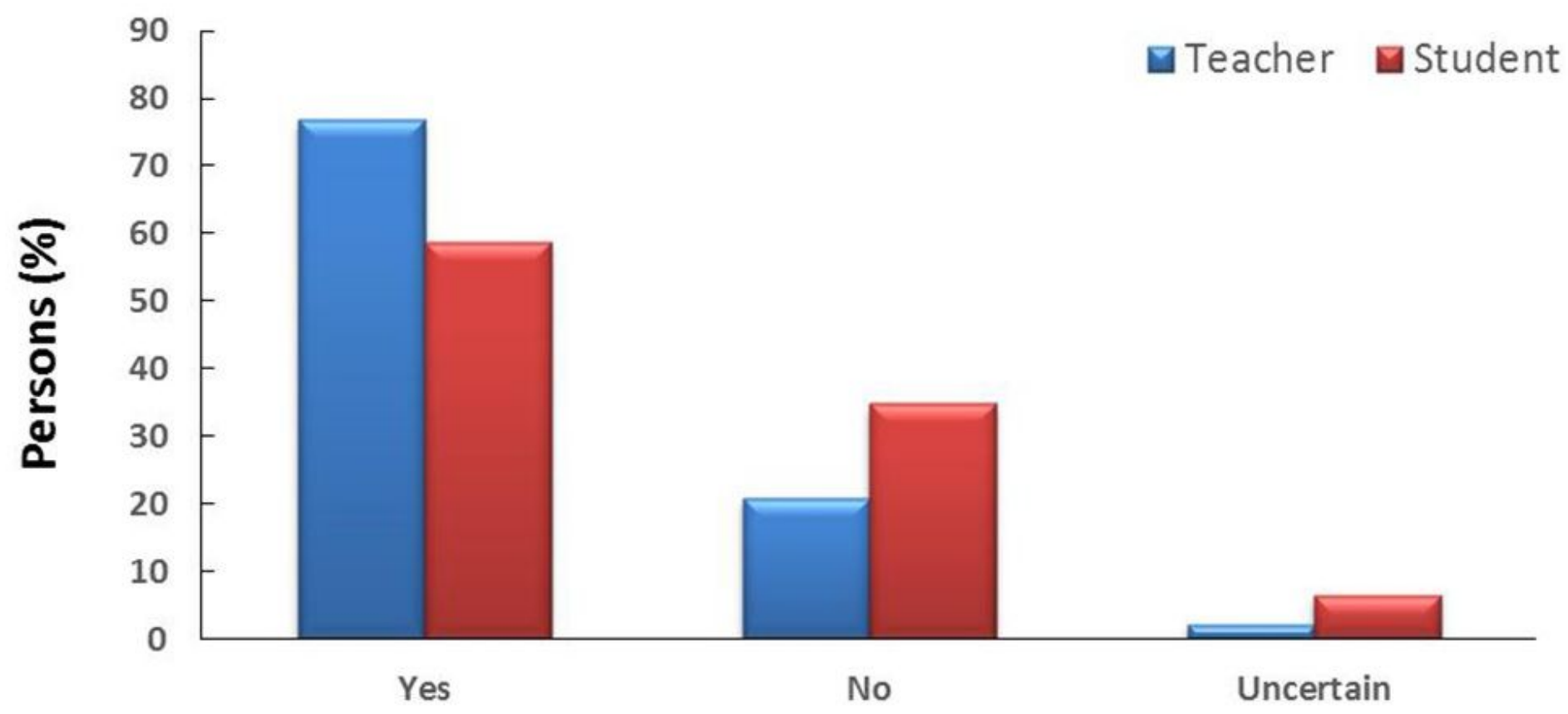

Figure 4

Pre-class training for teachers and students. Only $76.84 \%$ of teachers and $58.69 \%$ of students said they had received systematical distance online teaching training before the formal teaching or study. 


\section{Problems of online education}

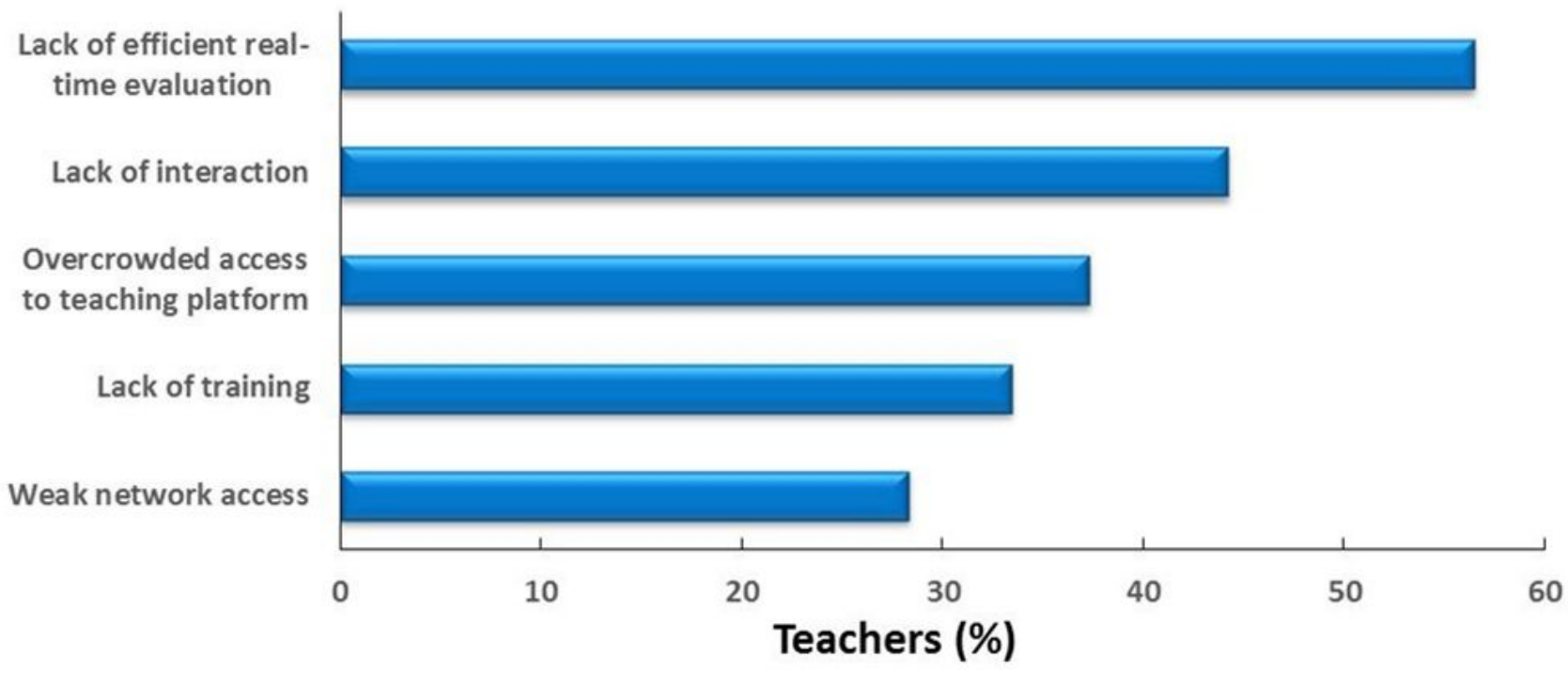

B

Problems of online education

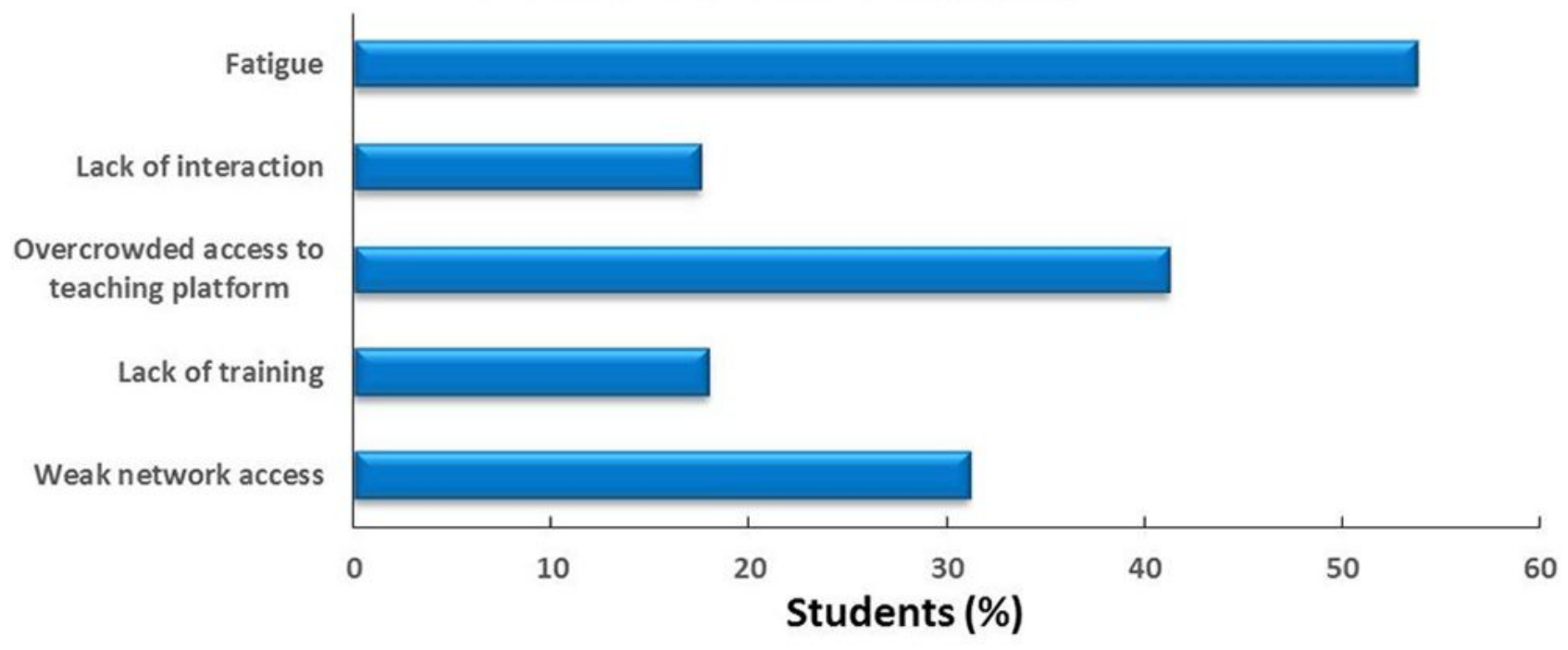

\section{Figure 5}

Teachers believed that the main problems of online education are lack of effective real-time evaluation (56.48\%), lack of interaction (44.24\%), overcrowded access to teaching platform (37.33\%), lack of training (33.45\%) and weak network access (28.35\%); Students believed that the main problems of online education are fatigue (53.75\%), lack of interaction (17.54\%), overcrowded access to teaching platform (41.19\%), lack of training (17.92\%) and weak network access (31.11\%). 